\title{
APROXIMACIONES A
}

\section{LA ECONOMÍA}

\section{POLÍTICA}

Anuar Vichara Chabur Martínez

Universidad Cooperativa de

Colombia

Sede Ibagué

\section{Apropiación social del conocimiento | Nota de clase \\ No. 33, diciembre de 2018 \\ doi: https://doi.org/10.16925/gcnc.04}

El presente documento de trabajo ha sido incluido dentro de nuestro repositorio de literatura gris por solicitud del autor, con fines informativos, educativos o académicos. Asimismo, los argumentos, datos y análisis incluidos en el texto son responsabilidad absoluta del autor y no representan la opinión del Fondo Editorial o de la Universidad.

\section{DISCLAIMER}

This coursework paper has being uploaded to our grey literature repository due to the request of the author. This document should be used for informational, educational or academic purposes only. Arguments, data and analysis included in this document represent authors' opinion not the Press or the University. 


\section{Acerca del autor}

Anuar Vichara Chabur-Martínez, economista, especialista en Docencia Universitaria, diplomado en Desarrollo Económico y Competitividad, diplomado en Pedagogía y Evaluación en la Formación por Competencias. Profesor auxiliar del programa de Derecho, Universidad Cooperativa de Colombia, sede Ibagué, Colombia. Correo electrónico: anuar.chabur@campusucc.edu.co

\section{Cómo citar este documento}

Chabur-Martínez, A. V. (2018). Aproximaciones a la economía política. (Documento de docencia $\mathrm{N}^{\circ} 33$ ). Bogotá: Ediciones Universidad Cooperativa de Colombia. doi: https://doi.org/10.16925/gcnc.04.

Este documento puede ser consultado, descargado o reproducido desde nuestro repositorio de documentos de trabajo (http://repository.ucc.edu.co/handle/ucc/7369) para uso de sus contenidos, bajo la licencia de Creative Commons Reconocimiento-NoComercial-SinObraDerivada 4.0 Internacional. http://creativecommons.org/licenses/by-nc-nd/4.0/ 


\section{Resumen}

Desde la existencia de la humanidad, se han presentado acontecimientos que bien vale la pena reseñar. El hombre, decía Aristóteles, es un ser social, político, pensante; características que permitieron su desarrollo y transformación (Sánchez-Vásquez, 2003). Engels (2013) decía que el trabajo funciona como estímulo para la transformación del mono en hombre, es en este punto en el que se centra este análisis: ¿puede el trabajo ser el determinante de la evolución del hombre?, ¿pueden las relaciones sociales de producción ser una estrategia de desarrollo económico?, ¿pueden ser una estrategia para generar riqueza? Resolver el problema económico es una tarea de vieja data, los primitivos establecieron relaciones sociales comunes para poder hacer frente a las necesidades del ser humano, es decir que se organizaron para solventar las vicisitudes del día a día, con frío, con hambre. El hombre debe apoyarse en otros hombres para salir adelante en el diario acontecer, de esta manera es que evolucionaron los modos de producción y sistemas económicos, tales como el primitivismo, el esclavismo, el feudalismo, el capitalismo y el socialismo.

Palabras claves: modos de producción, política, relaciones sociales, sistema económico. 


\section{Tabla de contenido}

Capítulo I. Aproximaciones a la economía política 8

$\begin{array}{lr}\text { Introducción } & 8\end{array}$

Conceptualización y contexto. Algunas aproximaciones a la economía política

¿Qué es economía?

¿Qué es política? 9

¿Qué es economía política? 10

¿Qué es la política económica? 11

El derecho y la economía política $\quad 12$

La ley de la escasez y la economía política $\quad 12$

Costo de oportunidad 13

Economía positiva y economía normativa 13

$\begin{array}{ll}\text { Sistema económico } & 13\end{array}$

Factores económicos 14

$\begin{array}{ll}\text { Sectores } & 16\end{array}$

$\begin{array}{ll}\text { Mercados } & 16\end{array}$

Agentes económicos 18

$\begin{array}{ll}\text { Sectores económicos } & 18\end{array}$

Objeto de estudio de la economía política 19

Desarrollo económico 20

Crecimiento económico 21

$\begin{array}{ll}\text { Pleno empleo } & 21\end{array}$

$\begin{array}{ll}\text { Estabilidad de precios } & 22\end{array}$

Redistribución del ingreso $\quad 22$

Bienestar económico 23

Libertad económica 23 
Problema económico 23

Medios de producción $\quad 23$

Método de estudio de la economía política 24

Método científico 24

Cuestionario y taller de repaso 25

$\begin{array}{ll}\text { Taller de repaso } & 26\end{array}$

$\begin{array}{ll}\text { Conclusiones } & 27\end{array}$

Capítulo II. Sistemas económicos $\quad 29$

Breve recuento $\quad 29$

$\begin{array}{ll}\text { Primitivismo } & 31\end{array}$

$\begin{array}{ll}\text { Características } & 31\end{array}$

$\begin{array}{ll}\text { Esclavismo } & 33\end{array}$

Características $\quad 33$

$\begin{array}{ll}\text { Feudalismo } & 35\end{array}$

Características $\quad 35$

$\begin{array}{ll}\text { Capitalismo } & 38\end{array}$

$\begin{array}{ll}\text { Características } & 38\end{array}$

Taller de repaso, análisis grafico $\quad 43$

$\begin{array}{ll}\text { Prueba conceptual } & 47\end{array}$

$\begin{array}{ll}\text { Prueba analítica } & 48\end{array}$

Conclusiones $\quad 49$

Referencias $\quad 51$ 


\section{Índice de figuras}

$\begin{array}{ll}\text { Figura 1. Sistema económico } & 14\end{array}$

Figura 2. Transformación del mono en hombre 15

$\begin{array}{ll}\text { Figura 3. El mercado } & 17\end{array}$

Figura 4. Esquema simple de economía convencional con externalidades 24

Figura 5. El esclavismo 34

Figura 6. Pirámide social en el feudalismo 37

Figura 7. Ejercicio de repaso n. ${ }^{\circ}$

Figura 8. Ejercicio de repaso n. ${ }^{\circ} 244$

Figura 9. Ejercicio de repaso n. ${ }^{\circ}$

Figura 10. Ejercicio de repaso n. ${ }^{\circ} 4$

Figura 11. Modelo de producción feudal 46 
Gracias a los estudiantes que hacen posible los siguientes avances de clase, ellos son producto de la interacción en las aulas, por ello invito a leer cuidadosamente las aproximaciones a la economía política. Las relaciones sociales que se evidencian en los salones de clase dan como resultado este trabajo, que nos lleva a cuestionar, indagar y ser propositivos en la búsqueda por construir un mejor país. 


\section{Capítulo I. Aproximaciones a la economía política}

\section{Introducción}

La sociedad evoluciona constantemente y a la economía política ${ }^{1}$ le corresponde analizar dicha evolución en materia económica. Desde el inicio de la humanidad nos relacionamos socialmente de una u otra manera con el fin de satisfacer necesidades; estas notas de clase exponen cómo fueron y cómo son las relaciones sociales de producción, distribución, consumo e intercambio.

Inicialmente, hay que precisar la conceptualización y contextualización, luego el objeto y método de estudio de la economía política. Al interior de la conceptualización se hace necesario conocer los términos: política económica, ley de la escasez, costo de oportunidad, economía positiva y normativa, factores económicos, sectores, para posteriormente dar cierre a esta sección con el funcionamiento del sistema económico capitalista.

Los hechos económicos inician con los sistemas políticos y el antagonismo de clases, así como con la dinámica histórica de las sociedades que presenta eventos muy significativos, desde la revolución industrial hasta nuestros días, con tecnologías que de una u otra forma, alteran las formas de relacionarse socialmente.

Estás notas de clase son para que el estudiante de derecho se haga responsable de conocer, analizar e interpretar los diferentes modos de producción presentados a través de la historia económica y desde la misma existencia del hombre. Explicar la importancia de la teoría del valor y la trascendencia del trabajo a través del tiempo; es importante saber los

1 Término utilizado por: Antonie de Montchrestien, 1615. 
acontecimientos económicos, políticos y sociales, hasta el siglo XXI, ello incluye las leyes del mercado.

El conocimiento de la economía política le permite al estudiante de derecho conocer la influencia político-social y a su vez comprender como la política, la normatividad influye sobre la economía.

\section{Conceptualización y contexto. Algunas aproximaciones a la}

\section{economía política}

\section{¿Qué es economía?}

Del griego oikos: casa (Soriano, 2005, p. 49) y nomos: ley (Jarrat, 1991). Economía es la ley de la casa y la casa es la sociedad. La ley equivale a las relaciones de poder de algunos individuos sobre otros individuos en la sociedad.

La economía es una ciencia social, histórica, interdisciplinaria, interdependiente, sistémica, sistemática, que estudia las relaciones sociales de producción, la distribución, el consumo e intercambio (leyes económicas) que se requieren para satisfacer las necesidades humanas, las cuales son de carácter ilimitado. Dichas necesidades se satisfacen con recursos escasos, con bienes y servicios limitados. Esta ciencia estudia las leyes del mercado, es decir la oferta y la demanda o las fuerzas del mercado que determinan la conformación del precio.

\section{¿Qué es política?}

Del griego polis (RAE, 2014): ciudad. En la ciudad habitan las personas y ellas conforman la sociedad y las relaciones sociales de producción, distribución, consumo e intercambio. Se deben regular las relaciones sociales y para ello 
se requiere del poder. Se afirma que la política es el arte de gobernar (Vilalta, 2012), el arte de ejercer el poder y direccionar la sociedad.

La [R]eal [A]cademia [E]spañola, dice que la política es el arte, doctrina u opinión, referente al gobierno de los estados, la actividad del ciudadano cuanto interviene en los asuntos públicos por medio de la opinión voto o cualquier otro modo. La intervención del hombre en lo social se convierte en una actividad que tiene como objetivo tomar ciertas decisiones que lo que hacen es transformar la realidad. Esto persigue objetivos para transformar la realidad a través del hombre. (Leyton, 2015)

\section{¿Qué es economía política?}

Antoine de Montchrestien describió la economía política haciendo referencia a las relaciones sociales de producción, distribución, consumo e intercambio entre las clases sociales en el capitalismo (Wikipedia, s.f.a). El antagonismo de clases hace referencia a la oposición y rivalidad que existe entre las clases sociales altas, medias y bajas; es decir, ricos y pobres, poseedores de los medios de producción y los desposeídos, capitalistas y obreros.

La economía política es, en su más amplio sentido, la ciencia de las leyes que rigen la producción y el intercambio de los medios materiales de vida en la sociedad humana. Producción e intercambio son dos funciones distintas. La producción puede tener lugar sin intercambio, pero el intercambio -precisamente porque no es sino intercambio de productos- no puede existir sin producción. (Engels, 1878, p. 139)

La economía política es una ciencia social-histórica, interdisciplinaria, interdependiente y sistemática que estudia las relaciones (sociales) de producción, distribución, consumo e intercambio para satisfacer las necesidades humanas, las cuales son de carácter ilimitado y se satisfacen con bienes y servicios o recursos escasos, limitados. Es por lo que se habla de las 
leyes de la producción, distribución, consumo e intercambio, ley de la escasez, ley de la oferta y la demanda (también se llaman leyes del mercado). Es decir que también estudia el mercado y su regulación por parte de la política económica, tales como la política fiscal, monetaria, crediticia y cambiaria, política laboral, agropecuaria, comercial e internacional.

\section{¿Qué es política económica?}

No se le debe confundir con la economía política, ya que la política económica es un instrumento de regulación de las relaciones sociales de producción, distribución, consumo e intercambio (Fernández, Parejo y Rodríguez, 2011). No se debe olvidar que la política económica dicta las leyes económicas que rigen la producción, distribución, cambio y consumo de bienes y servicios.

Política y economía son altamente interdependientes, se puede decir que lo político impacta lo económico y viceversa. Las dos ciencias (economía y política) tienen un compromiso en la organización del Estado y las relaciones sociales (relaciones de poder) entre gobernantes y gobernados. Los gobernantes y sus instituciones están tomando decisiones económicas permanentemente, con miras al servicio a la comunidad, en pos del desarrollo económico, crecimiento económico, empleo, redistribución de los ingresos, estabilización de los precios, entre otros. Siempre lo político y lo económico van de la mano.

También en términos coyunturales la integración es bastante clara: en cualquier sociedad, la inestabilidad de las instituciones políticas conduce fatalmente a la inestabilidad económica. Recíprocamente, la estabilidad y el desarrollo económico se encuentran entre los factores esenciales que condicionan la estabilidad de los centros de mando del poder político. (Rossetti, 1995, pp. 15-16) 


\section{El derecho y la economía política}

Por medio de las normas legales, el derecho determina a la sociedad, el tipo de sociedad, el tipo de sistema político, la libre iniciativa privada. La constitución política colombiana precisa el modelo de sistema actual, garantiza los derechos y establece los deberes.

En tanto ciencia, el derecho marca la ruta en materia económica política - social - ambiental. El derecho impone las leyes para producir, distribuir, consumir e intercambiar; el derecho permite o prohíbe actividades económicas en las cuales los hombres se relacionan y condicionan así las relaciones sociales. El derecho limita la libertad, la competencia, la oferta, la demanda y los precios, dichas limitaciones deben propender por el bienestar de la comunidad.

\section{La ley de la escasez y la economía política}

La economía se ha hecho llamar la ciencia de la escasez (Nikitin, 2012), siendo objetivos, nuestros recursos son cada vez más limitados, ello debido a la mala utilización de los mismos. El consumismo de la sociedad agota los recursos por el cambio climático, por la explotación de la naturaleza; la disponibilidad de recursos es poca, por ello hay que hacer un llamado a la conciencia del hombre. Nuestras tierras pierden fertilidad, la explotación minera reduce las aguas, contamina de manera alarmante. La insaciabilidad del ser pone en peligro la economía.

La paradoja del diamante es una buena explicación de la escasez y el valor (Wikipedia, s.f.b), esta afirma que el agua es vital y a pesar de ello vale poco, mientras que los diamantes valen mucho y no son vitales, ¿te preguntas por qué? Porque el agua es relativamente abundante y los diamantes son escasos. 


\section{Costo de oportunidad}

A manera de ejemplo, se explica el costo de oportunidad. Bajo el supuesto de que hay que elegir entre dos alternativas, $A \circ B$, si se opta por A, se sacrifica $\mathrm{B}$, entonces el costo de oportunidad es $\mathrm{B}$, lo que se deja de hacer o lo que se sacrifica es el costo de oportunidad. A este aspecto se le conoce también como la frontera de posibilidades de producción en una sociedad. Si un país desea incrementar la producción de arroz, supone entonces reducir la producción de algodón. Renunciar a la producción de algodón para poder producir más arroz recibe entonces la denominación de costo de oportunidad.

\section{Economía positiva y economía normativa}

Economía positiva o descriptiva. Es importante saber cómo funciona la economía realmente, esta se apoya en la experiencia, con lo que respecta a lo que fue (pasado), lo que es (presente) y el futuro, trata de predecir la economía.

Economía normativa. En párrafos anteriores se habló de política económica para expresar: juicios de valor, valores éticos basados en la teoría económica, lo que los pensadores proponían que debía ser la economía y cómo debía funcionar. Estas políticas forman parte de la agenda de los gobernantes, son los sueños de los gobernantes para sus gobernados.

\section{Sistema económico}

Un sistema económico es un conjunto de relaciones sociales interfactoriales, intersectoriales e interdependientes; son conexiones y dependencias en las cuales participa el hombre con su capacidad laboral. 


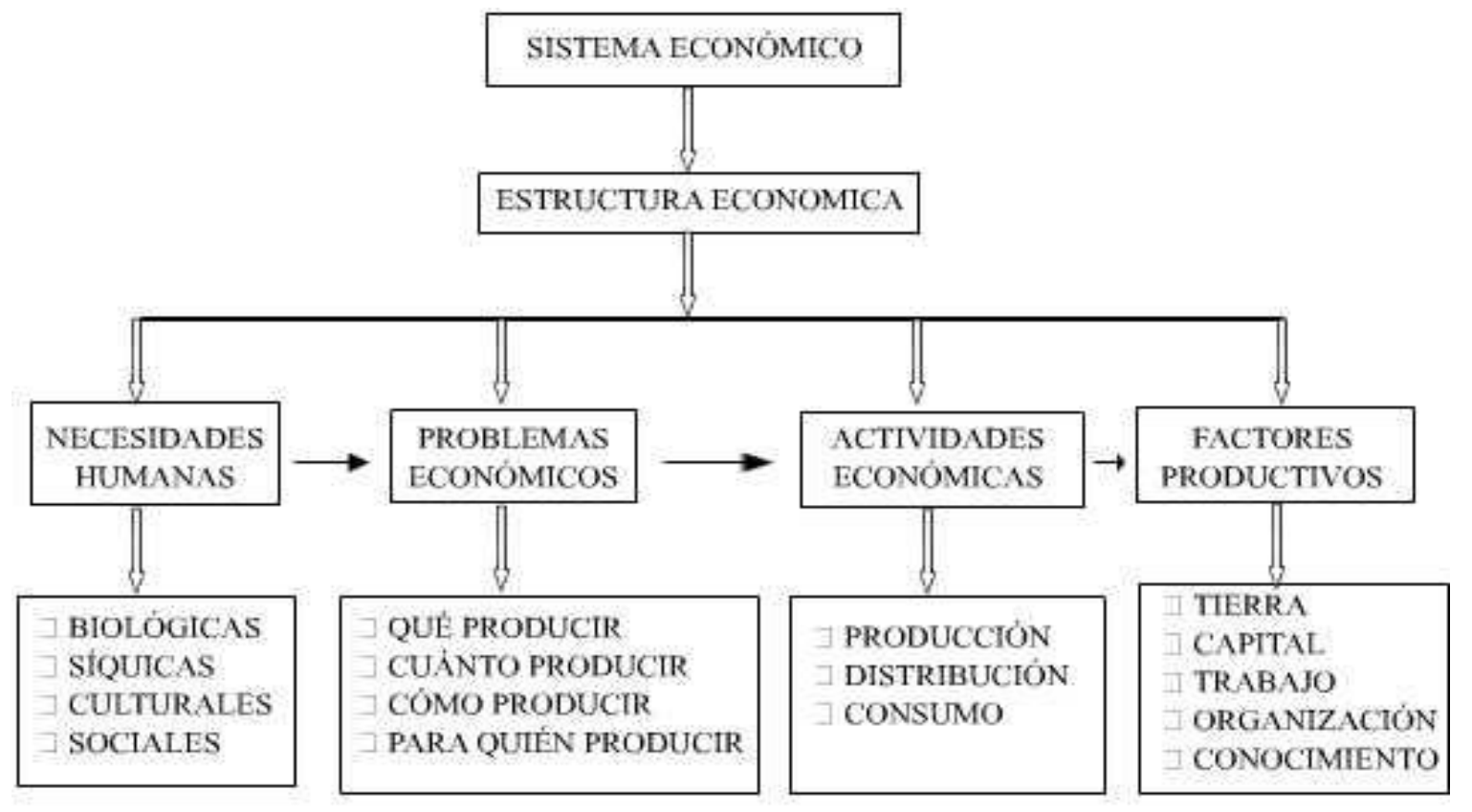

Figura 1. Sistema económico

Fuente: o_o (2006)

Como la economía es un sistema interdependiente e interdisciplinario, refleja relaciones sociales de producción, distribución, consumo e intercambio; relaciones entre factores económicos y sectores; relaciones interfactoriales e intersectoriales, y se conoce con el nombre de estructura económica y social. El enfoque sistémico de la economía trata de comprender el funcionamiento de la sociedad de manera integral. Responder a las necesidades del mercado y resolver el problema económico supone organizar la sociedad para satisfacer las necesidades humanas, para ello se requiere de factores económicos, agentes económicos, medios de producción y sectores (temas que se abordan a continuación). En otras palabras, es relacionarse en la producción, distribución, intercambio y consumo.

\section{Factores económicos}

También llamados factores de producción (Eco-finanzas, s.f.). 
- El factor tierra retribuye renta.

- El factor trabajo o mano de obra retribuye salario.

Engels afirmó que el trabajo transformó al hombre y escribió un texto al respecto, a saber, "El papel del trabajo y su transformación del mono en hombre" (Engels, 1895-1896)².

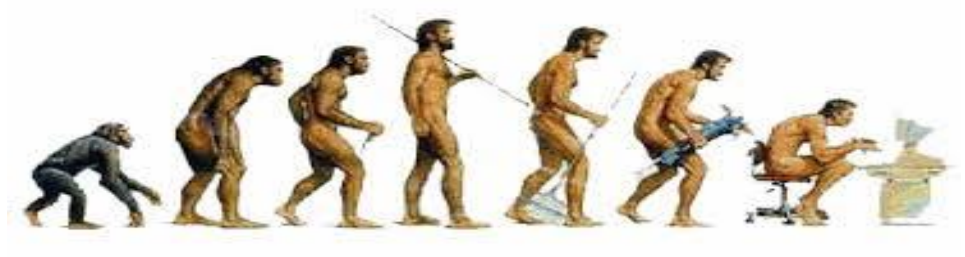

Figura 2. Transformación del mono en hombre

Fuente: Colussi (2010)

- El factor capital retribuye interés.

- El factor de gestión empresarial retribuye ganancias, utilidades y dividendos.

La sumatoria de la renta, salario, intereses, dividendos, ganancias y utilidades recibe el nombre de ingreso nacional; los ingresos se destinan al consumo y lo que sobra se ahorra. El consumo de bienes y servicios se realiza en el mercado de bienes y servicios y lo que sobra se lleva al mercado financiero y se ahorra. El mercado financiero paga intereses por los depósitos; esos depósitos financian la economía, es decir que se prestan y se cobra interés por el crédito.

De lo anterior se deduce que $\mathrm{Y}=\mathrm{C}+\mathrm{A}$

Y: ingreso; C: consumo; A: ahorro

Analizar esta equiación $\mathrm{A}=\mathrm{Y}-\mathrm{C}$

${ }^{2}$ Se recomienda Colussi (2010) para ahondar en el tema. 
Lo que se describe parcialmente en el párrafo anterior implica relaciones sociales que de una u otra forma, suponen relaciones de poder. Si se relaciona el factor tierra con el trabajo, se da una relación interfactorial entre la tierra y el trabajo, lo que significa que la tierra necesita de mano de obra. Si la tierra requiere de un tractor para su producción, es necesario relacionarla con el factor capital industrial o tecnológico, existen entonces relaciones interfactoriales.

\section{Sectores}

En los párrafos anteriores se hizo mención a las relaciones sectoriales e intersectoriales. Para aclarar un poco, cabe especificar que hay sectores sociales o agentes sociales y sectores económicos. Se puntualiza entonces:

Sectores sociales o agentes sociales: familias, empresas, administración pública y el resto del mundo.

- Las familias y las empresas conforman el sector privado.

- Las administraciones públicas conforman el sector público.

- El resto del mundo conforma el sector externo.

El sector privado se puede relacionar con el sector público y configura economías mixtas, allí se dan relaciones intersectoriales.

El sector privado se puede relacionar con el sector externo, lo cual da lugar a relaciones intersectoriales de orden internacional. Igualmente, el sector público se puede relacionar con el sector externo.

\section{Mercados}

- Mercado de bienes y servicios 
- Mercado financiero

- Mercado de capitales o de valores

- Mercado laboral

- Mercado de divisas

El mercado es un lugar -no necesariamente físico, también puede ser virtual-, un espacio en el cual se encuentran vendedores y compradores, se relacionan productores, consumidores y distribuidores que intercambian bienes y servicios a un precio que se fija de acuerdo con la oferta y la demanda, según las leyes del mercado.

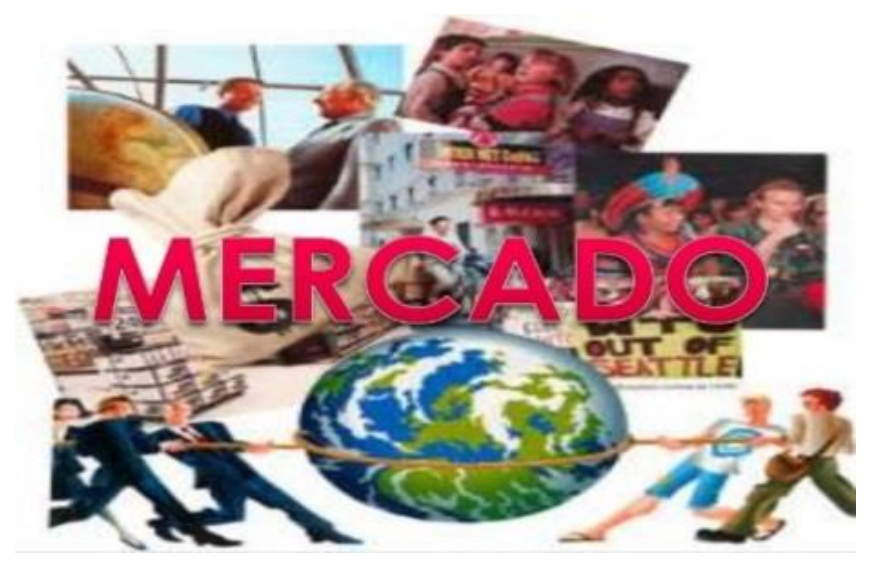

Figura 3. El mercado

Fuente: 01010139 (2013) 


\section{Agentes económicos}

Tabla 1.

Agentes económicos y sus funciones

\begin{tabular}{|c|c|c|c|}
\hline Agente & Función & Objetivo & Limitación \\
\hline Familias & Consumo. & $\begin{array}{l}\text { Satisfacer } \\
\text { necesidades. }\end{array}$ & $\begin{array}{l}\text { Ingresos o } \\
\text { preferencias. }\end{array}$ \\
\hline Empresa & Producción. & $\begin{array}{l}\text { Obtener máximo } \\
\text { beneficio. }\end{array}$ & $\begin{array}{l}\text { Presupuesto y } \\
\text { tecnología. }\end{array}$ \\
\hline Sector público & $\begin{array}{l}\text { Regular la } \\
\text { economía del } \\
\text { país. } \\
\text { Suministrar } \\
\text { bienes públicos. } \\
\text { Proporcionar } \\
\text { servicios } \\
\text { públicos. }\end{array}$ & $\begin{array}{l}\text { Maximizar el } \\
\text { bienestar de un país. } \\
\text { Mantener en } \\
\text { equilibrio las } \\
\text { relaciones } \\
\text { económicas dentro } \\
\text { del país y fuera de } \\
\text { este. }\end{array}$ & Ingresos públicos. \\
\hline Sector externo & $\begin{array}{l}\text { Consumo } \\
\text { Producción } \\
\text { (únicamente las } \\
\text { empresas). }\end{array}$ & $\begin{array}{l}\text { Satisfacer } \\
\text { necesidades. } \\
\text { Obtener } \\
\text { beneficios(solamente } \\
\text { económicos). }\end{array}$ & $\begin{array}{l}\text { Presupuesto y } \\
\text { tecnología. }\end{array}$ \\
\hline
\end{tabular}

Fuente: elaboración propia

\section{Sectores económicos}

Sector primario: se le conoce también con el nombre de agropecuario.

Sector secundario: se le conoce también con el nombre de industrial.

Sector terciario: se le conoce también con el nombre de comercio. 
Sector cuaternario: se le conoce también con el nombre de investigación, desarrollo e innovación.

En los sectores económicos hay familias, empresas, gobierno y multinacionales. Si el campesino en su finca produce (cultiva) algodón y lo vende a una industria para transformarlo en hilo, hay relaciones intersectoriales en la compraventa. Si la industria vende el hilo a la industria textil para hacer tejido plano, hay relaciones sociales entre el mismo sector. Los tejidos planos se vuelven camisas y van al sector comercial, por ende, existen entonces relaciones intersectoriales de la industria y el comercio. En conclusión, existe plena interdependencia sectorial y factorial y a ello se le denomina sistema.

Si el sector privado no se relaciona con el sector público ni el externo, hablamos de una economía no intervenida y cerrada. Si el sector privado se relaciona con el sector público, pero no con el sector externo, hablamos de una economía intervenida o mixta y cerrada. Si el sector privado se relaciona con el sector externo, hablamos de economías abiertas, internacionalizadas, globalizadas. Si se relacionan todos los sectores con todos, hay relaciones intersectoriales globalizados y regulados.

\section{Objeto de estudio de la economía política}

En la agenda de todos los gobernantes se puede apreciar los siguientes temas:

- Desarrollo económico

- Crecimiento económico

- Estabilidad de precios

- Estabilidad económica

- Pleno empleo

- Redistribución del ingreso 
- Libertad económica

- Bienestar económico ${ }^{3}$

Estos objetivos también están en la agenda de los empresarios y los políticos, sin discriminar, es decir que está en la agenda de todos.

Lo más importante es precisar cada uno. Se recomienda visitar la presentación que Andy99sr (2016) hace al respecto y que se puede encontrar en el siguiente enlace: https://www.emaze.com/@ACTCTFLL/crecimiento-ydesarrollo-economico

\section{Desarrollo económico}

Es calidad de vida, el mejorar las condiciones de vida; es bienestar para la sociedad, más y mejor producción, empleo e ingresos, mejor distribución de la riqueza, altos niveles nutricionales, bajos niveles de mortalidad y morbilidad, bajos o nulos niveles de analfabetismo; lo que en gasto público es inversión social e infraestructura. También aire limpio, producción limpia, no contaminación ni corrupción, mecanismos de participación efectiva, institucionalidad, gobernabilidad, confianza, credibilidad. Todos ellos están contemplados en el Índice para medir el Desarrollo Socioeconómico (IDSE) (El Orden Mundial en el s. XxI, 2015). El desarrollo humano es desarrollo socioeconómico, felicidad.

Su medición es cualitativa, el índice de Gini (Wikipedia, s.f.c) muestra la distribución del ingreso como medida del desarrollo. Vale recordar que el desarrollo económico es muy diferente al crecimiento económico.

\footnotetext{
${ }^{3}$ Los estudiosos de la hacienda pública lo interpretan como el gasto del gobierno en salud, educación, vivienda, defensa, justicia, entre otras.
} 


\section{Crecimiento económico}

El crecimiento económico se da cuando un país produce más bienes y servicios en un año o período de tiempo, usualmente se mide por semestres o trimestres, puede ser discrecional de quien ejerza el poder, para saber cómo está la economía. El Producto Interno Bruto (PIB) es el indicador del crecimiento económico de un país. Es el principal indicador económico de una nación. "P" equivale a la producción de bienes y servicios, "I" debido a que es interno, se refiere a la producción al interior de las fronteras (de nacionales y extranjeros), de ella se excluyen todos los bienes y servicios que no son el resultado de un proceso productivo (formalidad de los mercados legales). "B" equivale a bruto en tanto no se han hecho deducciones al mismo.

$$
\underline{P I B}=C+G G+I+X-M
$$

C: consumo de los hogares o familias

GG: gasto del gobierno o consumo del gobierno (gasto público, inversión pública)

I: inversión privada

$\mathrm{X}$ : exportaciones

M: importaciones

Por ejemplo, una industria tiene altos niveles de producción, pero contamina el medio ambiente, en ese caso puede existir crecimiento económico, pero no desarrollo económico.

\section{Pleno empleo}

Pleno empleo significa que quien busca empleo y está en edad laboral productiva, lo encuentra (dados los salarios reales), es decir que la población económicamente activa tiene una oportunidad verdadera para emplearse. La 
tasa de desempleo es una medida que permite conocer si hay generación de puestos de trabajo o destrucción de los mismos.

\section{Estabilidad en precios}

"[...] la estabilidad de precios se define como una situación en la cual en promedio y a medio plazo, los precios ni suben ni bajan, de modo significativo" (Bando de España BDE, s.f.).

Lo ideal es que la inflación sea baja y estable, para no perder la capacidad de compra y a futuro poder comprar lo que se compra hoy al mismo precio o con un costo menor. Si usted piensa como consumidor, le favorece que los precios bajen y que los salarios sean estables o incrementen. Si usted piensa como productor, le favorece vender a precios altos, pero a precios altos los consumidores compran poco.

El índice de precios al consumidor o índice de precios de consumo (IPC) mide la tasa de inflación, mide el comportamiento de los precios al consumidor al por menor, al detal.

El índice de precios del productor (IPP) mide la tasa de inflación, mide el comportamiento de los precios al productor al por mayor.

\section{Redistribución del ingreso}

Redistribuir el ingreso ayuda a evitar los extremos de riqueza y pobreza. Es desconcentrar la riqueza, que los ricos redistribuyan y otorguen a los más vulnerables. Hacer justicia distributiva es hacer justicia social, es luchar contra la desigualdad. Los gobernantes hacen política y distribuyen el ingreso desde la hacienda pública con impuestos progresivos sobre la renta, subsidios, regulación de servicios públicos, entre otros. 


\section{Bienestar económico}

Estar bien económicamente, supone contar de manera adecuada con salud, educación, vivienda, servicios básicos, defensa y justicia, tener lo necesario para salir o nunca tener que llegar a experimentar la pobreza; es vivir y morir dignamente.

\section{Libertad económica}

La libertad económica está garantizada por la Constitución Política de Colombia, título II (Banrepcultural, s.f.). Libertad económica significa que quien quiera hacer empresa lo puede hacer, quien quiera producir lo puede hacer; quien quiera distribuir lo puede hacer, quien quiera consumir lo puede hacer; pero siempre acorde a las normas vigentes. Las normas regulan las relaciones sociales de producir, distribuir y consumir, no se permite la anarquía.

\section{Problema económico}

\section{¿Qué, cómo y cuándo producir?}

La economía ha de responder a las siguientes interrogantes :

¿Qué producir?, ¿bienes y servicios?, ¿cuáles?, ¿los escasos?, ¿Cómo producir?, ¿con los medios de producción organizando recursos productivos?, ¿con los factores productivos?, ¿con los sectores sociales?, ¿con los sectores económicos?

\section{Medios de producción}

Son instrumentos, materiales y servicios que participan en la producción, por ejemplo: tractores, (máquinas), alicates (herramientas), plantas (edificios), autos, teléfonos, internet, entre otros. 
¿Cuándo producir?, ¿ya?, ¿mañana?, ¿a largo plazo?, ¿a corto plazo?, ¿a mediano plazo?,¿para quién producir?, ¿para mí?, ¿para usted?, ¿para la comunidad?, ¿para el barrio?, ¿para el país?, ¿para el mundo? ¿Cómo se distribuyen los bienes y servicios entre los miembros de la sociedad?

\section{Método de estudio de la economía política}

\section{Método científico}

En este caso, el método científico supone aplicar una metodología para comprender el estudio de la economía política. Es decir, emplear el método deductivo y el inductivo.

Método deductivo: pasar de lo general a lo particular. Para este método hay que plantear hipótesis, partir de realidades, de la experiencia.

Método inductivo: pasar de lo particular a lo general. Igualmente, necesita plantear hipótesis como ejercicio primigenio para emplear el método. El método formula principios, leyes, teorías y modelos económicos. Parte de la observación, de cuestionamientos, investigar, indagar, medir, validar, comparar, disertar, debatir, experimentar.

La figura 4 que encuentra a continuación puede orientarle, obsérvela, cuestiónela, investigue, indague, mida, compare, diserte, debata, experimente... ¿hay relaciones sociales de producción, distribución y/o intercambio?

Por ejemplo, observe las relaciones entre los mercados y las familias. Describa qué pasa en el esquema. Si desea describir las relaciones de las familias con todos los elementos del esquema, lo que debe formular es una interdependencia, una interrelación (siga las flechas), luego, si quiere hacer un análisis y hacer propuestas, prospectiva, debatir, etc., está llevando a cabo un pensamiento complejo. 


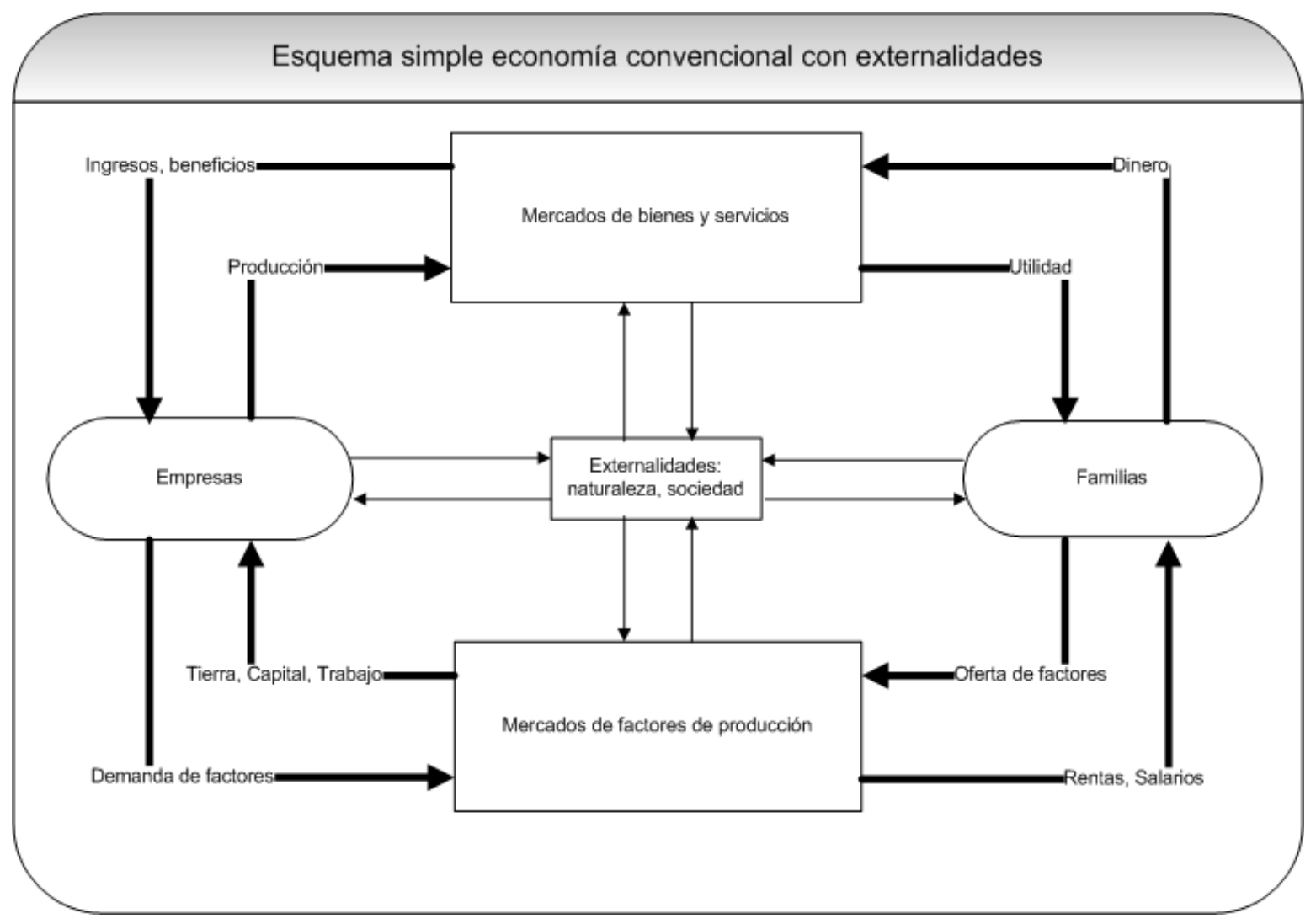

Figura 4. Esquema simple de economía convencional con externalidades Fuente: Macueconomía (2010)

\section{Cuestionario y taller de repaso}

1. Suponga que usted ha sido nombrado ministro de Hacienda y Crédito Público y tiene el compromiso de hacer realidad el objeto de estudio de la economía política. ¿Qué haría?

2. Los acontecimientos en la frontera colombo-venezolana tienen una relación íntima con el concepto de economía política. Diga si la aseveración anterior es falsa o verdadera y sustente su respuesta. Desarrolle pensamiento crítico.

3. El comportamiento fluctuante del precio del dólar es una realidad y ello ha significado un impacto sobre el producto interno bruto (PIB). Argumente la anterior idea. 
4. Los precios del petróleo han significado para Colombia una pérdida significativa en el ingreso de divisas. Argumente el porqué de dicha afirmación.

5. En Colombia y en algunos países del mundo se llevan a cabo por norma jurídica el día sin carro y sin moto, ¿qué efectos se podrían presentar sobre los siguientes aspectos?:
a) Agentes sociales
b) Sectores económicos
d) Sistema económico
e) El objeto de estudio de la economía

\section{Taller de repaso}

1. Diseñe un glosario y recuerde algunos de los conceptos básicos, tales como:

- Economía

- Política

- Economía política

- Política económica

- Escasez

- Costo de oportunidad

- Economía positiva

- Economía normativa

- Paradoja del diamante

- Problema económico

- Objeto de la economía política

- Medios de producción

- El papel del trabajo y su transformación del mono en hombre 
- Factores de producción

- Agente económico

- Mercado

- Sectores

- Sectores sociales

- Sectores económicos

- Sector primario

- Sector secundario

- Sector terciario

- Sector cuaternario

- Sistema económico

- Flujo circular del ingreso

- Oferta

- Demanda

- Precio

\section{Conclusiones}

Este primer capítulo aborda la parte conceptual, luego de su lectura debe quedar claro qué es economía política, es decir, que es una ciencia que estudia las relaciones sociales de producción; dicha producción se realiza para el consumo o el intercambio, por eso entre la producción y el consumo hay distribuidores.

Lo que estas notas de clase concluyen es que las relaciones en toda sociedad deben conducir al desarrollo económico, al crecimiento económico y con él, al empleo, la estabilidad, seguridad y redistribución del ingreso.

Toda economía debe buscar solucionar su situación económica con la ayuda de los factores económicos, medios de producción, agentes sociales y sectores, en últimas: familias, empresas, sector público, sector privado, 
sector externo. Todos los anteriores conforman el sistema económico, el cual será dinámico en la medida en que sus protagonistas lo estimulen para el bienestar general de la población.

Si se quiere hacer ciencia, basta con ser propositivo para dar solución a los problemas económicos, comprender las relaciones intersectoriales, interfactoriales, interagentes y ser participativo en las decisiones políticas.

Quienes participan de este curso, podrán presentar alternativas sobre qué, cómo, dónde y para quién producir. En su formación como abogados, los estudiantes de derecho tienen una gran oportunidad para participar con sus criterios políticos en pos de una mejor calidad de vida y apoyar el desarrollo competitivo. 


\section{Capítulo II. Sistemas económicos}

\section{Breve recuento}

Escribir acerca de los sistemas de producción o modos de producción -en lo que respecta a esta guía- supone hacer una aproximación a la economía política. No se trata de hacer un estudio profundo, esta guía orienta básicamente sobre las relaciones sociales de producción, distribución, consumo e intercambio; hace énfasis en que todas las épocas han sido difíciles en materia de explotación de los recursos naturales (tierra), explotación de la mano de obra (trabajo), escasez de capital financiero y tecnológico, y, por último, en habilidades gerenciales.

Las relaciones sociales son conflictivas, a veces generan procesos violentos -entiéndase guerras, desarraigo, cambio de costumbres, violaciones a los derechos humanos, movimientos migratorios de descubridores, invasiones, desplazamientos, conquistadores, colonizadores, despojo de riquezas representadas en los principales factores productivos (tierra, mano de obra)- en la búsqueda por la acumulación de capital. La ambición por el oro y metales preciosos son determinantes, el deseo de tener bienes materiales, dominar a los pueblos, ejercer el poder militar, religioso, económico y político, de alguna manera entorpecen las relaciones sociales. Quienes ejercen el poder dominan, quienes ejercen el poder lo ejercen a la fuerza, dominan con el cambio de cultura, con la política, y someten económicamente a los pueblos.

En este capítulo -y en general en esta guía- interesa abordar el capitalismo y su fase superior el imperialismo. En consecuencia, se han de señalar algunas características de cada sistema, con el ánimo de hacer la disertación y argumentaciones correspondientes en el aula, para poder 
construir conocimiento y pensamiento crítico y llegar a lo más complejo de los análisis.

Es muy importante tener claridad sobre la terminología desarrollada en el primer capítulo, los conceptos y el contexto. Se sugiere repasar los siguientes términos:

- Primitivismo

- Esclavismo

- Feudalismo

- Capitalismo

- Socialismo

- Fuerzas productivas

- Relaciones de producción

- Valor de uso

- Valor de cambio

- Mercancía

- Dinero

- Crédito

- Inflación

- Deflación

- Hiperinflación

- Estanflación

- Trabajo

- Clase social

- Antagonismo de clases

- Anarquía

- Competencia

- Plusvalía

- Fetichismo

- División del trabajo 
- Salario

- Precio

- Ganancia

- Explotación

- Producción mercantil simple

- Producción mercantil capitalista

Antes de abordar los modos de producción, es bueno hacer un breve recuento. Al inicio se habló de relaciones sociales de producción, es decir, relaciones entre los seres humanos, quienes se deben organizar para darle solución a los problemas económicos o a lo que se identifica como un sistema económico.

En este apartado se hace referencia a los modos de producción o sistemas económicos y sus principales características que se han desarrollado a través de los tiempos. Dichas características ilustran y permiten llegar a comprender las complejidades intrínsecas a la materia y emprender los estudios que pueden clarificar el sistema económico dominante de hoy en día.

\section{Primitivismo}

\section{Características}

Se le conoce también como comunidad primitiva. De este sistema económico interesa destacar las siguientes características:

- Hombres salvajes

- Producción natural

- Nómadas

- Propiedad colectiva 
- Trabajo comunitario

- No hay propiedad privada

- No hay clases sociales

- No hay antagonismos de clase

- No hay lucha de clases

- Relaciones sociales comunitarias

- No explotación del hombre por el hombre

- Autoconsumo

- Auto subsistencia

- No hay excedente económico

- Medios de producción primitivos

- El principal medio de producción es la comunidad

- Primera división social del trabajo: caza y pesca-agricultura y pastoreo

- Segunda división social del trabajo: caza y pesca-agricultura y pastoreo-oficios

- Tercera división social del trabajo: caza y pesca-agricultura y pastoreooficios-comerciantes

Estas divisiones se dan en la medida en que el sistema va evolucionando y desapareciendo lentamente, mientras se inició una etapa de transición, por eso es necesario aclarar que bajo este modo de producción las labores se asignan de acuerdo con el género y la edad de las personas.

Con el uso del agua, el hombre se convierte de cierta manera en sedentario, pule sus medios de producción y mejora instrumentos para la caza y la pesca. De igual manera, la propiedad deja de ser comunitaria y pasa a ser familiar, la lucha contra la naturaleza facilita generar algún excedente de producción, que a su vez se intercambia por otros bienes. Lentamente se van dando situaciones especiales que dan origen a otro tipo de sistema económico, ya que estas permiten la aparición de la propiedad privada, el 
trueque, la explotación, inicia entonces un modo de producción llamado esclavismo.

\section{Esclavismo}

\section{Características}

Las características por resaltar sobre este sistema económico son:

- Hombres explotadores: amos, esclavistas

- Hombres explotados: esclavos

- Clases dominantes: amos, esclavistas

- Clases dominadas: esclavos

- Clase poseedora: amos, esclavistas

- Clase desposeída: esclavos

- No hay libertad

- Producción agrícola

- Producción ganadera

- Construcción

- Uso de metales

- Sedentarismo

- Propiedad privada

- Trabajo explotado

- Aparición de clases sociales: amo-esclavo

- Antagonismos de clase: amo-esclavo

- Lucha de clases: amo-esclavo

- Relaciones sociales dominantes: amo-esclavo

- Explotación del hombre por el hombre: amo-esclavo

- Consumo

- Excedente económico 
- Mejores medios de producción

- Mayor división del trabajo: comerciantes

- Desarrollo de la cultura greco-romana, egipcia-babilónica-fenicia

- El principal medio de producción es el trabajo esclavo

En un debido momento, las relaciones sociales de producción entre amo y esclavos empezaron a resultar entorpecedoras para la dinámica económica, tanto que los esclavos evidenciaron desmotivación, no producían ya y se revelaron ante las presiones de los esclavistas. Lo anterior fue dando cierre al modo de producción esclavista y entrada a otro modo de producción provocado por la liberación de los esclavos y la entrega que se hizo a los mismos de algunas tierras para cultivar. Fue así como, poco a poco, inició el feudalismo.

La figura 5 ayuda a comprender el esclavismo con gran claridad.

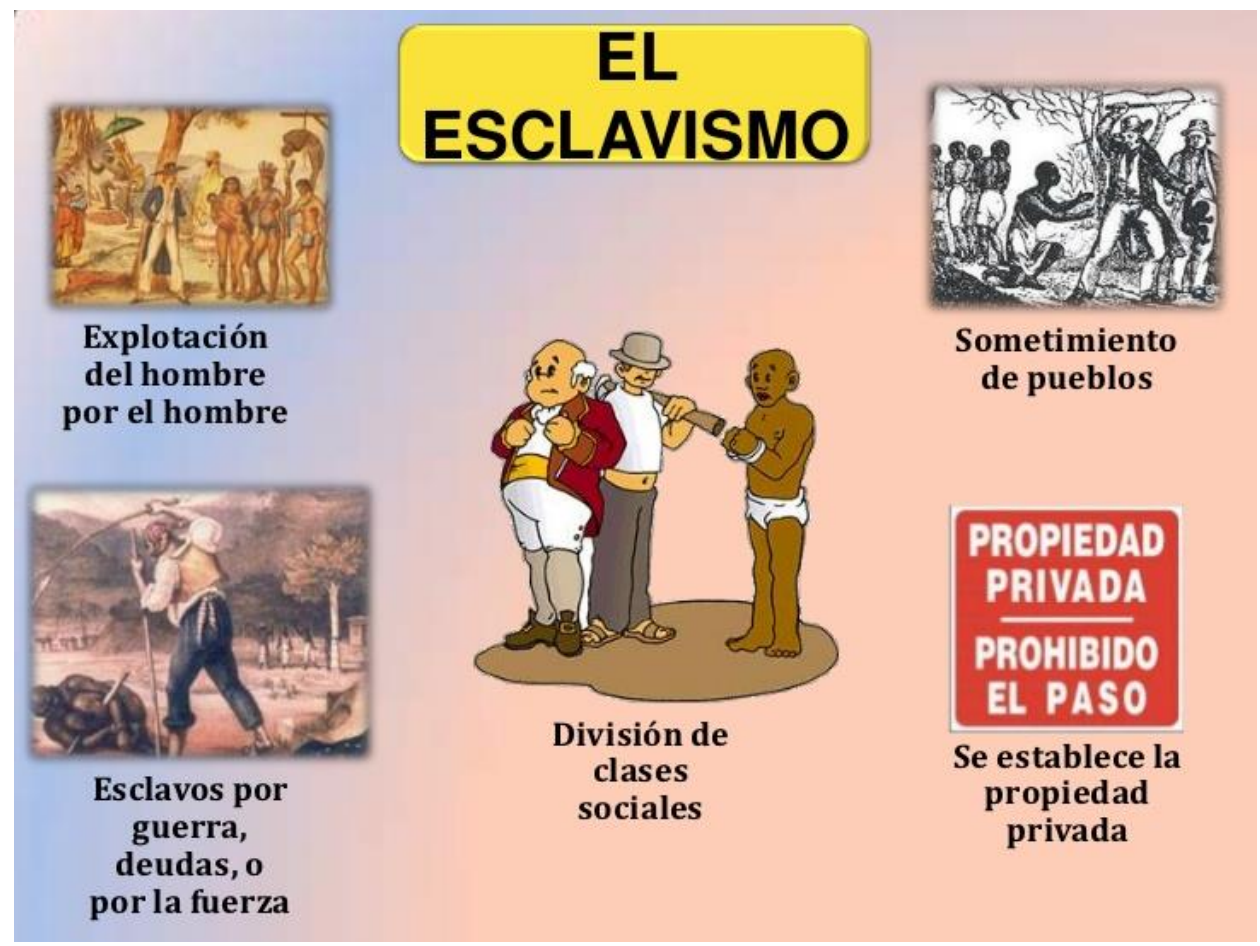

Figura 5. El esclavismo

Fuente: Giovanni (2015) 


\section{Feudalismo}

\section{Características}

Las características importantes para abordar sobre este sistema económico se enumeran a continuación:

- Edad media

- Aparición del feudo: tierra

- Emergencia de la servidumbre: siervo-campesino

- Inicio de la renta del suelo

- Advenimiento de la libertad relativa

- Hombres explotadores: señores feudales

- Hombres explotados: siervos de la gleba, vasallos

- Clases dominantes: señores feudales

- Clases dominadas: siervos de la gleba

- Clase poseedora: señores feudales

- Clase desposeída: siervos de la gleba

- Producción agrícola para el autoconsumo, no para comerciar

- Producción ganadera para el autoconsumo, no para comerciar

- Ausencia de intercambio

- Autarquía

- Uso de metales

- Sedentarismo

- Propiedad privada

- Implementación siervos de la gleba de burgos

- Creación de las ciudades

- Aparición de centros comerciales y artesanales, guildas ${ }^{4}$

\footnotetext{
${ }^{4}$ Guilda (del antiguo neerlandés gilde) es una corporación de mercaderes o comerciantes; una forma habitual de asociación durante la Baja Edad Media. Funcionaba institucionalmente de forma equivalente a los gremios de artesanos, es decir, como la reunión de un grupo de personas que
} 
- Talleres artesanales: maestros-oficiales-aprendices

- Existencia

- Emergencia de gremios productivos

- Trabajo explotado

- Trabajo necesario

- Trabajo adicional

- Plus producto

- Clases sociales: señores feudales- siervos de la gleba

- Antagonismos de clase: señores feudales- siervos de la gleba

- Lucha de clases: señores feudales- siervos de la gleba

- Relaciones sociales dominantes: señores feudales- siervos de la gleba

- Explotación del hombre por el hombre: señores feudales- siervos de la gleba

- Consumo

- Excedente económico

- Mejores medios de producción

- Mayor división del trabajo

- El principal medio de producción es la tierra (feudo)

En la figura 6 se pueden observar las clases sociales y por ende, la manera en la que se establecen las relaciones sociales.

comparten una actividad común, eligen cargos directivos, se dotan a sí mismos de reglas determinadas que obligan a todos ellos y comparten los mismos derechos o libertades. (Wikipedia, s.f.d) 


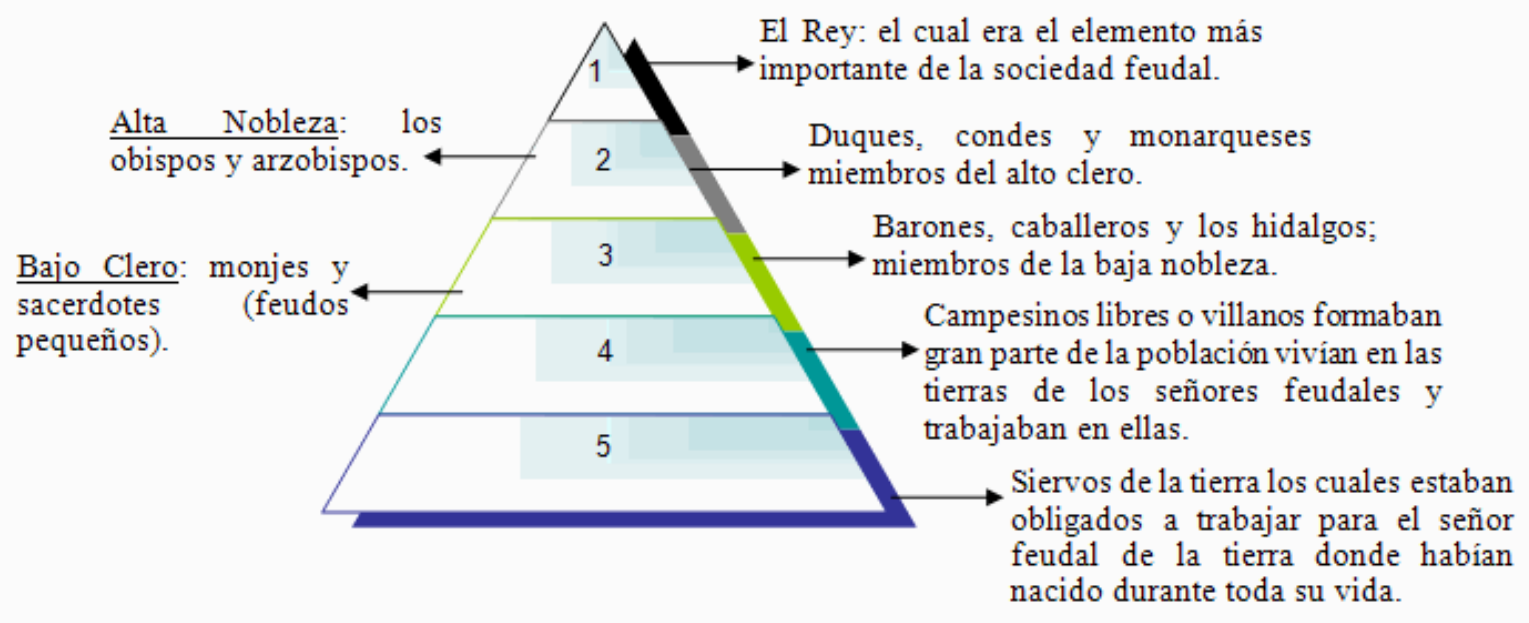

Figura 6. Pirámide social en el feudalismo

Fuente: Maria Lucia (s.f.)

La política, la iglesia y la economía son muy importantes para hacer los análisis complejos y desarrollar pensamiento crítico.

Con la agonía del feudalismo aparecieron indicios de una producción suficiente para el intercambio; en el feudalismo la producción reducía sus funciones al consumo directo para satisfacer las necesidades humanas de los señores feudales, de los siervos de la gleba y los demás grupos poblacionales que se especifican en la figura 6.

Quienes tenían acceso a la producción de mercancías (consumidores) y quienes tenían los medios de producción (productores) enfrentaron grandes diferencias y antagonismos de clase, desequilibrios en las relaciones sociales, anarquía de la producción y del consumo (indisciplina del consumidor), y competencia en el sistema económico. Poco a poco fueron emergiendo los principios de un nuevo sistema: el capitalismo.

Con la llegada del capitalismo, se debe abordar también la producción mercantil simple. Para ello, las presentes notas de clase se apoyan en los trabajos del filósofo y economista alemán, estudioso del capitalismo, que 
escribió El capital, Carlos Marx, para quien hizo de la mercancía parte fundamental de su argumentación.

\section{Capitalismo}

\section{Características}

Las características de este sistema económico que resulta importante destacar son las siguientes:

- Herencia feudal

- Renacimiento

- Presencia de dominio colonial

- Acumulación primitiva del capital

- Mercancía

- Dinero

- Aparición de capitalistas

- Aparición de obreros

- Pre-monopolio

- Monopolio, imperialismo

- Trabajo asalariado

- Revolución burguesa

- Revolución Industrial

- Libre competencia

- Desarrollo del mercado nacional e internacional

- Renta del suelo, renta de la mano de obra, renta del dinero y renta de la gestión empresarial

- Libertad relativa

- Hombres explotadores

- Hombres explotados

- Clases dominantes 
- Clases dominadas

- Clase poseedora

- Clase desposeída

- Producción mercantil simple

- Valor de uso

- Producción mercantil capitalista

- Valor de cambio

- Producción manufacturera

- Intercambio

- Uso de metales

- Sedentarismo

- Propiedad privada

- Centros comerciales

- Talleres especializados

- Creación de gremios

- Trabajo abstracto

- Trabajo explotado

- Trabajo necesario

- Trabajo adicional

- Plus producto

- Plusvalía

- Clases sociales

- Antagonismos de clase

- Lucha de clases

- Relaciones sociales dominantes

- Explotación del hombre por el hombre

- Indisciplina del consumidor

- Anarquía de la producción

- Excedente económico 
- Mejores medios de producción, tecnología

- Mayor división del trabajo, mayor especialización

- El principal medio de producción es el capital

- Capital comercial

- Capital financiero

- Capital tecnológico

- Emergencia de sociedades anónimas

- Concentración del capital

- Exportación de capitales

- Alianzas empresariales, multinacionales-, transnacionales

- Reparto territorial

- Dominio territorial

- Neocolonialismo

- Desigualdad

- Atraso

- Dependencia

- Presencia de ciclos económicos

- Capitalismo de Estado

Es muy importante tener dominio sobre los temas enumerados con anterioridad para comprender el sistema capitalista.

Cabe recordar que hay un concepto aproximado de economía política, junto con otros conceptos que resultan útiles para avanzar el desarrollo de este capítulo. Vale la pena recalcar sobre la importancia de la política, las apreciaciones sobre el objeto de estudio de la economía política, medios de producción, agentes, factores, sectores, problema económico, escasez, sistema económico, mercado, renta, salario, ingreso, consumo, ahorro, inversión, interés y ganancia, entre otros. 
Siendo que ya se abordaron brevemente los sistemas económicos precapitalistas (primitivismo, esclavismo, feudalismo), es hora de ocuparse del capitalismo, el cual se gestó en los sistemas antecedentes.

Para referirse al capitalismo, el punto de partida, necesariamente, es la propiedad privada sobre los medios de producción y la libertad económica o libertad de mercado (oferta y demanda). El capitalismo tiene varias etapas:

1. Etapa 1: siglo XVI, se caracteriza por una gran riqueza de oro, plata, platino y otros metales preciosos, que luego empiezan a ser acumulados por algunos europeos (occidente).

2. Etapa 2:_siglo XVII, inicia la acumulación de capitales, la cual impacta a la sociedad a todo nivel (económico, social, político, etc.). El aumento de capitales en poder de la banca inglesa da lugar a un portafolio de servicios financieros, básicamente seguros (custodia de dinero) y especulación.

3. Etapa 3: siglo XVIII (alrededor de 1780, Revolución Industrial), las empresas producen el capital con la explotación del hombre (obrero) por el hombre (patrón, burgués) a cambio de un pago (salario). Este tipo de relación social de producción supone una lucha de clases que pone en desventaja al obrero, lo somete a la explotación, y a su vez, produce más capital para el patrón; de esta manera, el sistema capitalista sigue evolucionando hasta generar el capitalismo financiero.

4. Etapa 4: siglo XIX, emergen desequilibrios, monopolios y alianzas empresariales (trust). Paulatinamente, se llega a un imperialismo de tipo económico y al auge del capitalismo financiero. Con la creación de compañías de seguros y la custodia de dineros, el crédito va incrementando sus ganancias y por supuesto mejora la seguridad del capital financiero y el capital industrial, revestido todo de un gran poder. La acumulación de dinero otorga poder, la no posesión de dinero conlleva vulnerabilidad. Debido a que esta condición pone al obrero en 
desventaja frente al patrón, los obreros se organizan en sindicatos para protegerse de los empleadores. Esta etapa, bien podría abarcar hasta nuestros días, con otro tipo de capitalismo, propio de la ventaja que adquieren los países ricos sobre los pobres (capitalismo periférico). Los países ricos, así como los pobres buscan mercados. Los países ricos alcanzan excesos de capital que ponen al servicio de países con escasez de capital (países pobres).

Los países en vías de desarrollo tienen sectores, como el agrario (producción de materias primas o commodities) y el comercio, más avanzados en producción y dependen de los países ricos para que se los compren (dependencia económica). Además, los países menos desarrollados presentan una pequeña sociedad burguesa y burocrática con nexos internacionales que aprovechan la producción campesina sin valor agregado (materia prima) para venderla a un precio muy bajo a países desarrollados, los cuales transforman la materia prima y la venden de vuelta con mayor valor adicional a un precio más alto. Como consecuencia, sus ganancias incrementan.

La mercancía (libro, cama, vestido, etc.) y el dinero (pesos, dólares, marcos, oro, moneda de cada país y o región), son temas sensibles para este capítulo. Para explicarlo, se utiliza el ejemplo de una silla: la silla sirve para sentarse, es decir su valor de uso (utilidad) es permitir el acto de sentarse. La silla sirve para ser intercambiada, es decir su valor de cambio (el precio de una silla $=\$ 100.000$ pesos, por ende, $\$ 100$ pesos $=1$ silla). Existen relaciones sociales en la producción de la silla, en su venta, en su consumo. La silla satisface una necesidad humana (valor de uso), pero la silla puede venderse y es posible obtener ganancias. Estas dos situaciones chocan, si no hay una acción de venta, tampoco hay una acción de consumo, en otras palabras, si en una tienda hay una manzana, es posible identificar su valor de uso, pero ese valor está latente, aunque sea un alimento, su valor de cambio debe demostrarse antes de ser consumido, si nadie lo compra, se bota, aunque exista gente que padezca de hambre. 
El trabajo (mano de obra), ya sea calificado o no, es otro tema sensible; se habla de tiempo de trabajo socialmente necesario (tiempo requerido para la producción), ese tiempo le da un valor a una mercancía. Es por ello que si para producir una silla se necesita una dedicación de dos horas, su valor será de $\$ 100.000$ pesos, pero si para producir una silla una persona se gasta cuatro horas, no por ello incrementará su valor a \$200.000 pesos, seguirá costando \$100.000 pesos porque el tiempo socialmente necesario se estableció en dos horas.

\section{Taller de repaso, análisis gráfico}

Analice las siguientes figuras y asigne un título acorde para cada una.

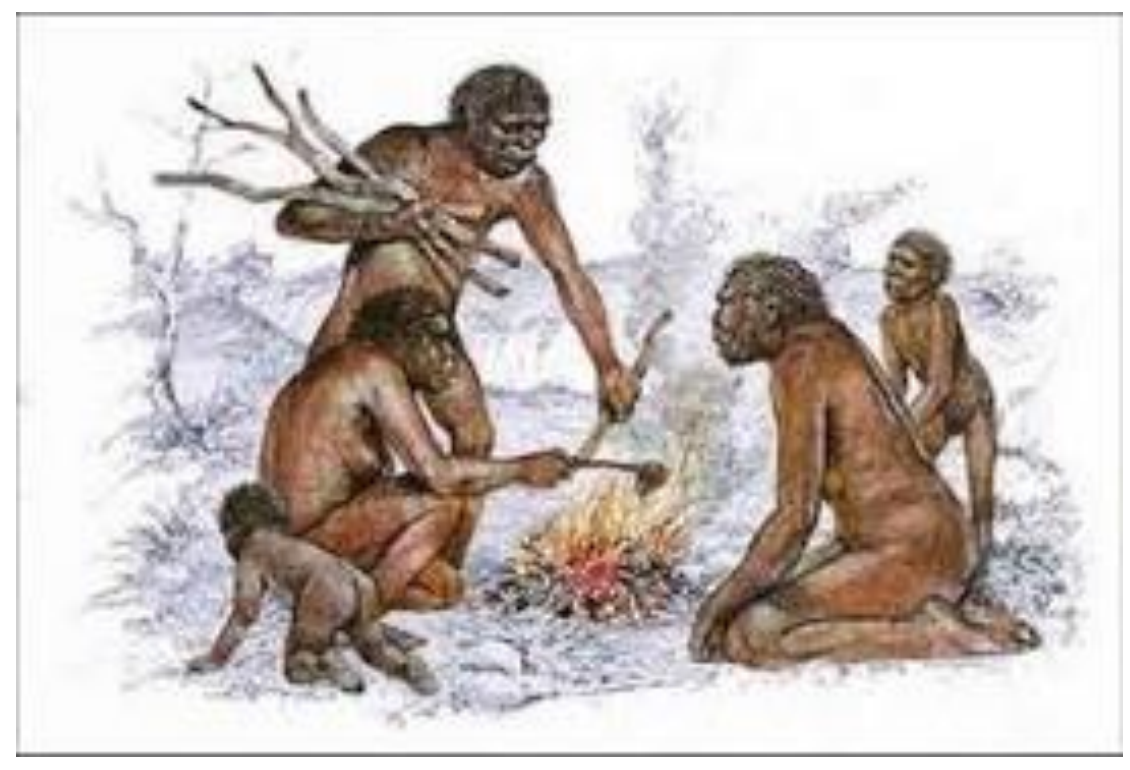

Figura 7. Ejercicio de repaso n. ${ }^{\circ} 1$

Fuente: Modos de producción (s.f.) 


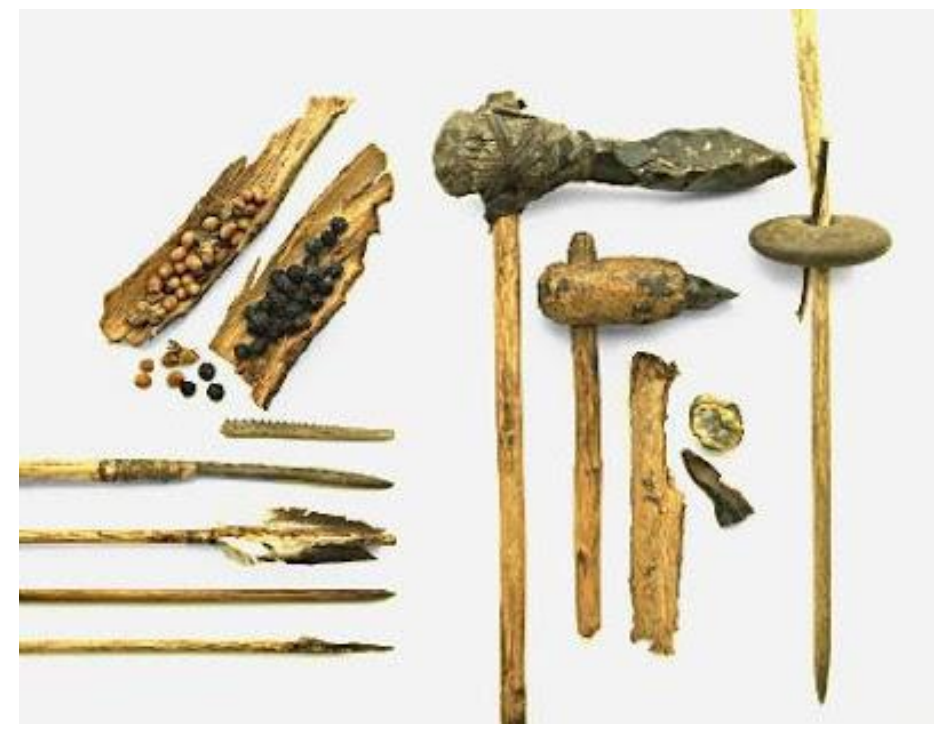

Figura 8. Ejercicio de repaso n. ${ }^{\circ} 2$

Fuente: Arreola, Alcaraz, Barragán, Cernas y Rodríguez (2009)
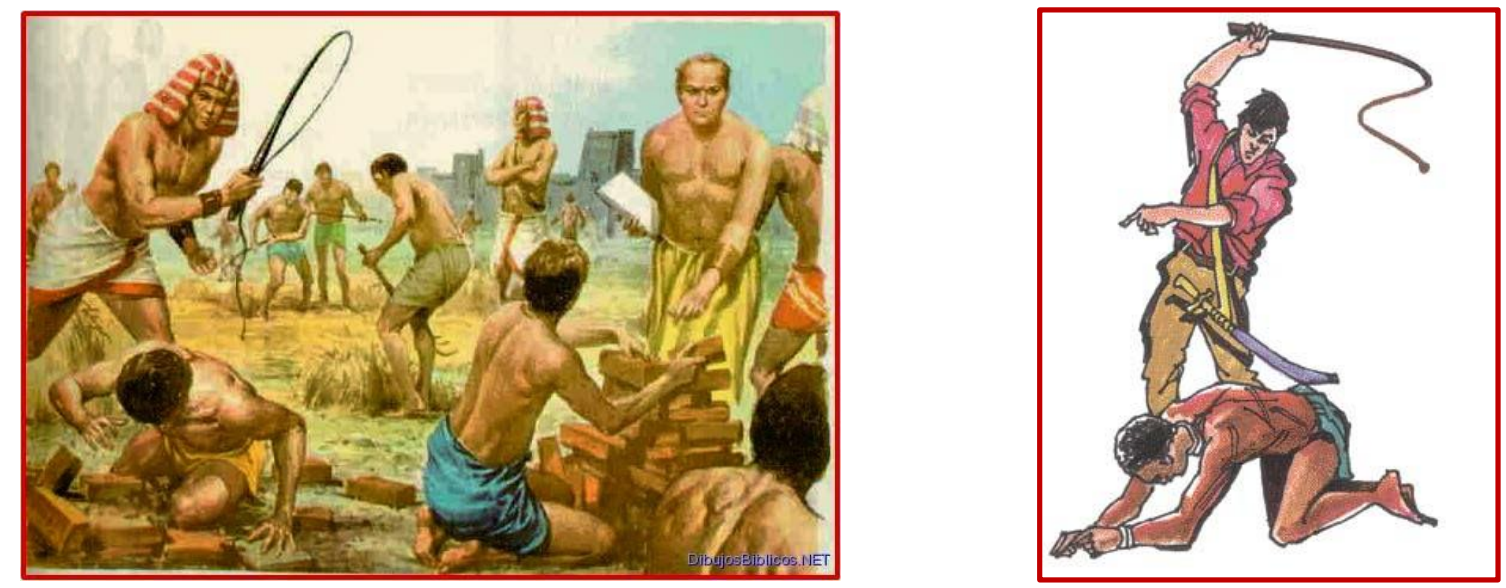

Figura 9. Ejercicio de repaso n. ${ }^{\circ} 3$

Fuente: Comité Estudiantil de Resistencia (2015) 


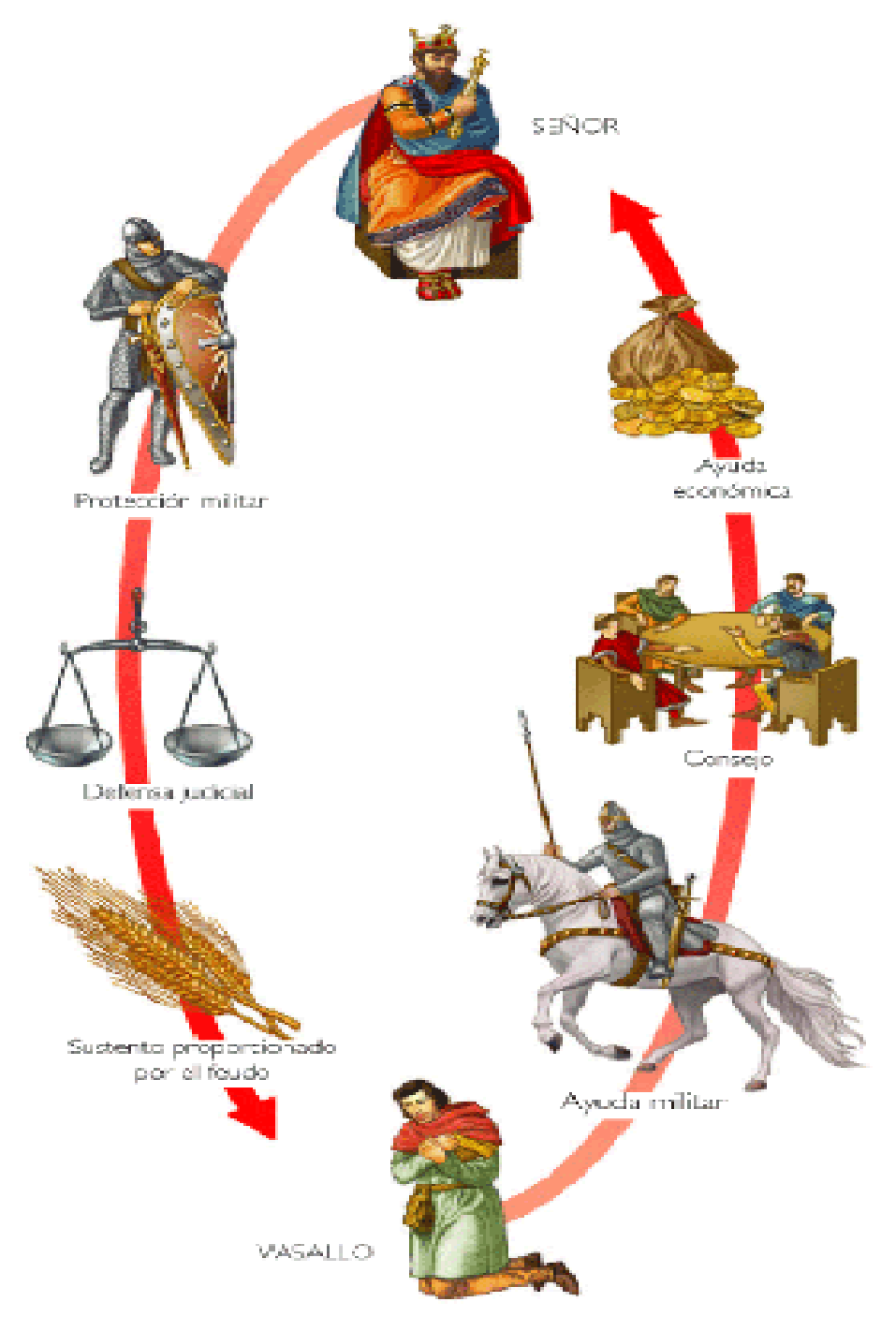

Figura 10. Ejercicio de repaso n. ${ }^{\circ} 4$

Fuente: Restaurante Beltane (2013)

En una página, escriba a qué se refiere el modelo de producción feudal, puede ser útil que consulte la figura 11 para ello. 


\section{MODELO DE PRODUCCIÓN FEUDAL}

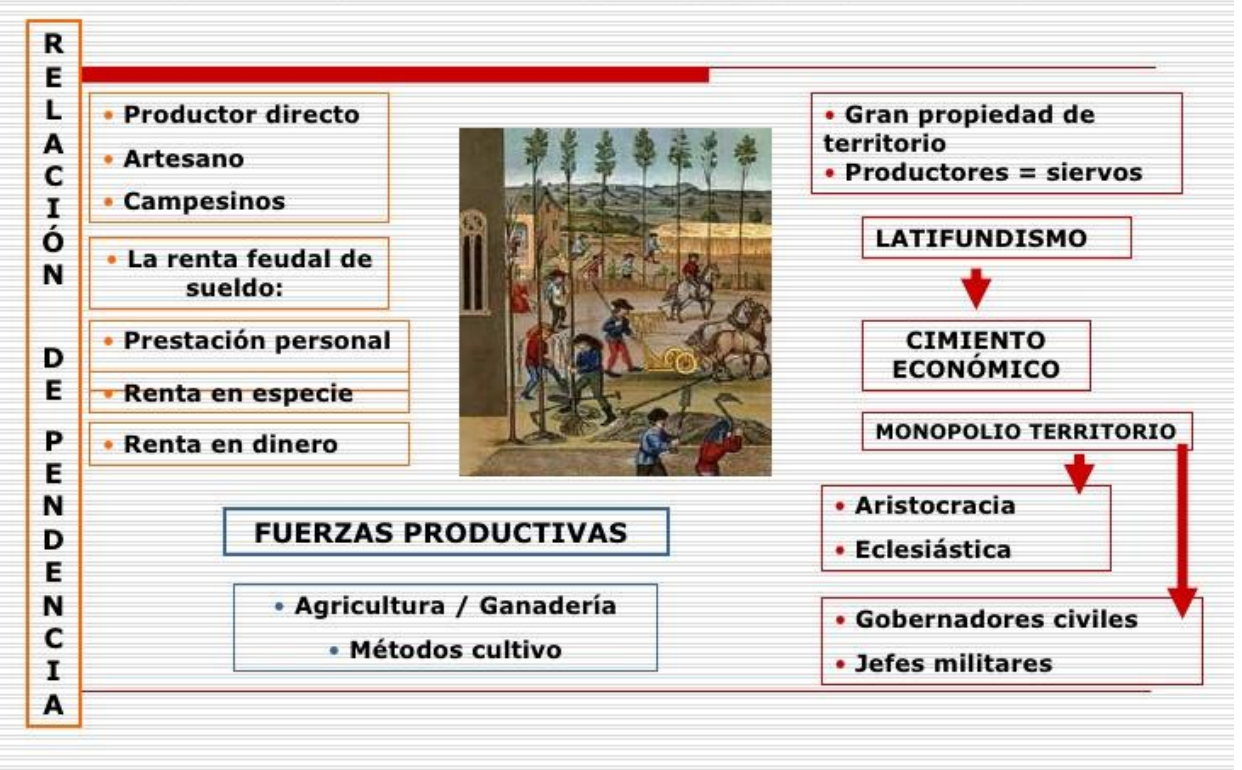

Figura 11. Modelo de producción feudal

Fuente: Yelitzi (2010)

Ingresa

a

esta

página

web

http://warmakunapa.blogspot.com.co/2015/08/ddd.html y explora, navega el sitio y escribe algún comentario después de ver video que se encuentra en este.

Si bien estas notas de clase culminan acá, el tema es muy amplio y esto es un abrebocas, no se pretende agotar el tema sino llevar esta información a las aulas y con apoyo de material audiovisual. En un twitter educativo, se hizo una selección de audiolibros muy completo que sirve como apoyo para el estudio de los temas acá esbozados. Su enlace es: https://twitter.com/UCCEcopolitica. Asimismo, se recomienda visitar: http://chabur.blogspot.com.co/ https://plus.google.com/104522668678021726753 para luego discutir el acontecer económico y proponer soluciones al problema económico desde la 
visión amplia del abogado de profesión. Se invita a los lectores de la presente a indagar sobre los siguientes términos y temáticas:

Mercantilismo, fisiocracia, clásicos, mano invisible, keynesianismo, monetarismo, colonialismo, neoliberalismo, imperialismo, PIB, IPC, IPP, tasa de cambio, exportar, importar, devaluación, revaluación, enfermedad holandesa, tasa de interés, tasa de captación, tasa de colocación, margen de intermediación financiera, TRM, DTF, geografía social, geopolítica, Consenso de Washington, estupidez humana, crematística, commodities, ventaja comparativa, ventaja competitiva, variables Y, X, M, I, C, GG, A, déficit fiscal, balanza de pagos, balanza en cuenta corriente, desarrollo económico, crecimiento económico, pleno empleo, redistribución del ingreso, estabilidad económica, estabilidad en precios, seguridad económica, libertad económica, estado de bienestar, lucha de clases, proletariado, movilidad social, dinero, liquidez, privatizar, desregulación del mercado, intervencionismo, poder, barreras, fronteras, arancel, parancel, doctrina Monroe, doctrina Truman, Plan Marshall, destino manifiesto, teoría del derrame, agregados económicos.

Averiguar sobre lo anterior permite resolver la siguiente actividad.

\section{Prueba conceptual}

¿Qué es y qué estudia la economía política?

- ¿Qué es y qué estudia la política?

- ¿Qué es y qué estudia la política económica?

- ¿Cómo se define el costo de oportunidad?

- ¿En qué consiste el objeto de estudio de la economía política?

- ¿Qué es un commodity?

- ¿Qué es ventaja comparativa? 
- ¿Qué es crematística?

- ¿Qué es geopolítica?

- ¿A qué se refiere el término de enfermedad holandesa?

\section{Prueba analítica}

1. Explique cómo y por qué la revaluación del peso colombiano afecta a las siguientes variables: PIB, C, A, I, GG, X, M, empleo, TRM, DTF, deuda externa, inversión extranjera y déficit fiscal.

2. Explique, en términos de política keynesiana, cómo se puede estimular la demanda agregada y el PIB.

3. A partir de la información encontrada en el blog Economía política5, nterprete los discursos de José Mujica, Fidel Castro, Manfred Max Neef, José Pablo Fiednman, Chomsky y Sanpedro, así como sus efectos sobre los agentes económicos.

4. ¿El Consenso de Washington impacta a los sectores y agentes económicos con el mercado? Argumente su análisis.

5. Existen muchas estrategias de dominación de masas, mencione cinco y explique una de ellas.

Al completar los ejercicios anteriores, estará en capacidad de responder lo siguiente:

1. ¿Por qué según Engels el trabajo es la fuente de toda riqueza?

${ }^{5}$ Visite http://chabur.blogspot.com.co/ y https://plus.google.com/104522668678021726753 
2. Cómo y por qué afecta la revaluación del peso colombiano a las siguientes variables: PIB, C, A, I, GG, X, M, empleo, TRM, DTF, deuda externa, inversión extranjera y déficit fiscal.

3. Explique con la política keynesiana cómo se puede estimular la demanda agregada y el PIB.

4. Suponga que usted es un líder político y se le pide combatir el desempleo y la inflación, ¿qué propondría teniendo en cuenta el contexto social y la historia del país?

5. Diseñe un mapa conceptual del sistema económico.

6. Analice, separe, resuma, interprete y luego integre los videos de José Mujica, Fidel Castro, Manfred Max Neef, José Pablo Fiednman, Chomsky y Sanpedro. Relacione esto con el Consenso de Washington, los sectores económicos, los agentes económicos, el mercado, etc.; que se encuentra en el blog de Economía política.

7. Formule una pregunta de análisis con carácter rizomático que involucre los temas del primer punto.

\section{Conclusiones}

La economía política muestra que el hombre ha querido satisfacer sus necesidades -que cada vez son mayores (ilimitadas)-, que, desde inicios de la humanidad, la dinámica supuso que los hombres se relacionaran para resolver los problemas económicos: qué producir, cómo, cuánto, para qué y para quién, con qué y con quién, dónde, entre otros. Son muchos los interrogantes a resolver. Las respuestas se dan en el seno de las relaciones sociales de producción, que en un principio fueron comunes, no había antagonismo de clases, regía el principio de "todos somos iguales", no había propiedad privada y aparentemente, todo marchaba bien. Luego surgieron otras formas de relacionarse en las cuales prima el desequilibro y unos 
empiezan a tomar ventaja de otros. Surge entonces la lucha de clase, entre los dueños de los medios de producción y los desposeídos que trabajan dichos medios, son relaciones que entorpecen la dinámica en la sociedad y generan desigualdad.

Las familias fueron adquiriendo importancia para el desarrollo de las relaciones sociales, se le asignó a cada integrante una serie de responsabilidades; adicionalmente, hay jerarquías que responden a la antigüedad, de alguna forma, el anciano tiene el poder y lo ejerce para el bien de la familia.

Con la aparición de la propiedad privada se marcó una diferencia mayúscula, puesto que mientras algunos se hicieron dueños de los medios de producción, otros no y esto terminó por alterar la tranquilidad de la sociedad y generó la necesidad de poner un orden en las relaciones sociales, consecuentemente, surgió el Estado. La aparición del Estado se gesta con el poder: quien ejerce el poder domina. El poder lo adquieren quienes acumulan bienes materiales, la religión, la fuerza y poco a poco, emerge la política, que es una forma de dominar; la política es poder, supone gobernar sobre un otro.

Las dinámicas en la producción, distribución, consumo e intercambio fueron adquiriendo un tinte conflictivo, la escasez, mala distribución y características fisiográficas de cada región dieron pie para que surgieran políticas que orientan la economía.

Mediante la economía política se busca que las relaciones de poder o las relaciones de producción beneficien a la sociedad, contribuyan al desarrollo económico, al pleno empleo, a la redistribución de la riqueza, a la estabilidad económica, a la seguridad económica, a la justicia y defensa de la economía, entre otros. 


\section{Referencias}

Althusser, L. (2014). La revolución teórica de Marx. Bogotá: Siglo XXI editores.

Andy99sr (2016, mayo 11). Crecimiento y desarrollo económico [Presentación en diapositivas]. Emaze. Amazing presentations. Recuperado de https://www.emaze.com/@ACTCTFLL/crecimiento-y-desarrolloeconomico

Arreola, G., Alcaraz, J., Barragán, V., Cernas, K., y Rodríguez, M. (2009, septiembre 11). Modos de producción. Fundamentos Economía [entrada blog]. Recuperado de http://fundamentoseconomiia.blogspot.com.co/2009/09/modos-deproduccion.html

Banco de España (BDE). (s.f.). Estabilidad del sistema de precios. Aula virtual del Banco de España. Eurosistema [en línea]. Recuperado de http://aulavirtual.bde.es/f/webaula/INF/Estabilidad-deprecios/precios.pdf

Banrepcultural (s.f.). Constitución Política de Colombia de 1991. Enciclopedia de Banrepcultural. Red Cultutral del Banco de la República de Colombia. Recuperado de http://enciclopedia.banrepcultural.org/index.php?title=Constituci\%C 3\%B3n_Pol\%C3\%ADtica_de_Colombia_de_1991\#T.C3.ADtulo_II:_De_1 os_derechos.2C_las_garant.C3.ADas_los_deberes

Castro, A., y Lessa, C. (1995). Introducción a la economía (35º ed.). Un enfoque estructuralista. Bogotá: Siglo xxi editores.

Chabur, A. (2016a). Economía política. Recuperado de https://twitter.com/UCCEcopolitica

Chabur, A. (2016b). Economía política [blog]. Recuperado de http://chabur.blogspot.com.co/ 
Chabur,

A.

(2016c).

Recuperado

de https://plus.google.com/104522668678021726753

Colussi, M. (2010, diciembre 3). El papel del trabajo en la transformación del hombre en mono [entrada blog]. El socialismo es la solución blogspot. Recuperado de http://socialismosolucion.blogspot.com.co/2010/12/el-papel-del-trabajo-en-la.html

Comité Estudiantil de Resistencia (2015, enero 18). Formación básica i: Modos y relaciones de producción. Estudiar, organizar, resistir [entrada blog]. Recuperado de http://cercordoba.blogspot.com.co/2015/01/formacion-basica-i.html

Eco-finanzas. (s.f.). Factores de producción. Diccionario. Eco-finanzas. Recuperado de http://www.ecofinanzas.com/diccionario/F/FACTORES_DE_PRODUCCION.htm

El Orden Mundial en el s. Xxi. (2015, octubre 27). Un nuevo indicador para medir el desarrollo: el Índice de Desarrollo Socioeconómico (IDSE). Dipublico.org. Derecho Internacional. Recuperado de https://www.dipublico.org/103068/un-nuevo-indicador-para-medirel-desarrollo-el-indice-de-desarrollo-socioeconomico-idse/

Engels, F. (1878/2000). I. Objeto y método. Sección Segunda. Economía Política. En La revolución de la ciencia de Eugenio Dühring ("anti-Dühring") (pp. 139-150). Moscú: Instituto del Marxismo-Leninismo y Editorial Progreso. Marxists Internet Archive. Recuperado de https://www.marxists.org/espanol/m-e/1870s/anti-duhring/adseccion2.htm

Engels, F. (1895-1896/2000). El papel del trabajo en la transformación del mono en hombre. Marxists Internet Archive. Recuperado de https://www.marxists.org/espanol/m-e/1870s/1876trab.htm

Fernández, A., Parejo, J. A., y Rodríguez, L. (2011). Política económica. España: McGraw Hill Interamericana de España. 
Foreman Peck, J. (2001. Historia Económica mundial: relaciones económicas internacionales desde 1850. España: Prentice Hall.

Galbraith, J. K. (1983). El dinero. Barcelona: Ediciones Orbis.

Galbraith, J. K. (1984). El nuevo estado industrial. España: Sarpe.

Giovanni (2015, mayo 2). Modo de producción esclavista. Modo de producción esclavitud [entrada blog]. Recuperado de http://produccion001.blogspot.com.co/2015/05/produccion.html

Heilbroner, R. (1984). Vida y doctrina de grandes economistas. Toledo: Ediciones Orbis.

Herrerías. (s.f.). Principios de Economía Política.

Huberman, L. (2005). Los bienes terrenales del Hombre. Bogotá: Génesis.

Recuperado de https://issuu.com/lacajadepandora7/docs/los_bienes_terrenales_del_ hombre_--

Jarrat, S. C. (1991). Rereading the Sophists: Classical Rhetoric Refigured. Carbondale: Southern Illinois University Press.

Kenessey, Z. (1987., diciembre). The Primary, Secondary, and Quaternary Sectors of the Economy. The Review of Income and Wealth, 33(4), 359 385. doi: https://doi.org/10.1111/j.1475-4991.1987.tb00680.x

Kuczynski, J. (1978). Breve historia de la Economía. Bogotá: El Faro.

Leyton, A. (2015, septiembre 7). ¿Qué es política etimológicamente? Economía Política [entrada en blog]. Recuperado de http://economiapoliticagrupoucc.blogspot.com.co/

Macueconomía. (2010, noviembre 14). Hablamos de ... los sistemas económicos! [entrada blog]. Recuperado de http://inmaeconomia.blogspot.com.co/2010_11_01_archive.html 
Maria Lucila. (s.f.). El feudalismo. Monografías.com [en línea]. Recuperado de http://www.monografias.com/trabajos61/feudalismo/feudalismo.sht $\mathrm{ml}$

Marx, K. (2014). La ideología alemana. Madrid: Ediciones Akal

Marx, K. (1983a). El Capital (Tomo 1). España: Sarpe.

Marx, K. (1983b). El Manifiesto del Partido Comunista. España: Sarpe.

Méndez, J. S. (2002). Fundamentos de economía (3a ed). México: Mc Graw Hill.

Modos de producción (s.f.). Consumismo primitivo [entrada blog]. Recuperado de https://sites.google.com/site/modosdeproduccionnt/comunismoprimitivo

Nikitin, P. (2012). Economía política. Bogotá, Colombia: Editorial Atenea.

Real Academia Española (RAE). (2014). Diccionario de la lengua española (23ed.). Madrid: Editorial Espasa Calpe.

Restaurante Beltane (2013, febreroo 15). Feudalismo [entrada blog]. Recuperado de https://restaurantebeltane.wordpress.com

Rossetti, J. P. (1995). Introducción a la Economía (15º ed.). México: Harla.

Samuelson, P. (1983). Economía desde el corazón. Barcelona: Orbis S.A.

Sánchez Vázquez, A. (2003). Filosofía de la praxis. Edición ilustrada. Editor siglo XXI

Schumacher, E. F. (1983). Lo pequeño es hermoso. Barcelona: Ediciones Orbis.

Shumpeter, J. A. (1983). Capitalismo, socialismo y Democracia (Tomos I y II). Barcelona: Ediciones Orbis.

Smith, A. (1983). La riqueza de las Naciones. Tomo I. Barcelona: Ediciones Orbis.

Soriano, P. (2005). La mediación figurativa como historia del habitar. Público y privado (vol. 2). Buenos Aires: Nobuko. 
Thurow, L. C. (1983). La sociedad suma cero. Barcelona: Orbis S.A.

Ugaz Salvatierra, F. (2015, agosto 29). Modo de producción capitalista. Warmakunapa Amawtan [entrada blog]. Recuperado de http://warmakunapa.blogspot.com.co/2015/08/ddd.html

Vilalta, M. (2012, abril 17). La política como arte de gobernar. Excelsior. Recuperado de http://www.excelsior.com.mx/opinion/2012/04/17/maruxavilalta/826972

Wikipedia. La enciclopedia libre (s.f.a). Economía política [entrada enciclopedia en línea]. Recuperado de https://es.wikipedia.org/wiki/Econom\%C3\%ADa_pol\%C3\%ADtica

Wikipedia. La enciclopedia libre (s.f.b). Paradoja del valor [entrada enciclopedia en línea]. Recuperado de https://es.wikipedia.org/wiki/Paradoja_del_valor

Wikipedia. La enciclopedia libre (s.f.c). Coeficiente de Gini [entrada enciclopedia en línea]. Recuperado de https://es.wikipedia.org/wiki/Coeficiente_de_Gini

Wikipedia. La enciclopedia libre. (s.f.d). Guilda [entrada enciclopedia en línea]. Recuperado de https://es.wikipedia.org/wiki/Guilda

Yelitzi, V. (2010, enero 5). Modelo de producción feudal. Slide Share [presentación de diapositivas en línea]. Recuperado de http://es.slideshare.net/YELITZI/modelo-de-produccin-feudal

o_o (2006, agosto 20). N. N. [entrada blog]. lalexemedejaterriblehardkore.blogspot. Recuperado de http://lalexemedejaterriblehardkore.blogspot.com.co/2006_08_01_ar chive.html 
01010139 (2013, mayo 18). Presentación de Mercado [diapositiva]. Slide Share. Recuperado de http://es.slideshare.net/01010139/presentacin-demercado 
